\title{
Device Friction Problem Identified
}

National Cancer Institute

\section{Source}

National Cancer Institute. Device Friction Problem Identified. NCI Thesaurus. Code C92056.

Problems caused by its surface coming in contact with another surface or fluid. 